\title{
Cuidado e doença crônica: visão do cuidador familiar no Nordeste brasileiro
}

\author{
Care and Chronic Illness: \\ Family Caregiver's Viewpoint in Northeast Brazil
}

Juliana Maria de Sousa Pinto ${ }^{1}$

Marilyn Kay Nations ${ }^{1}$

${ }^{1}$ Centro de Ciências da Saúde, Universidade de Fortaleza. Av. Washington Soares 1321/S01, Edson

Queiroz. 60811-341

Fortaleza CE.

jumsp@hotmail.com

\begin{abstract}
The provision of care causes stress in everyday family dynamics leading to physical, mental and emotional complications in caregivers and spouses' loss of liberty and/or overwork. Between March and November 2006, this anthropological research examined family caregiving in the context of Chronic Obstructive Pulmonary Disease (COPD). By means of ethnographic interviews, illness narratives and participant observation, the scope was to describe family reorganization and coexistence with the disease and its evolution, caregiver perceptions about patient difficulties and limitations experienced and strategies employed to tackle their illness. Six low-income family caregivers, living in poor, urban areas in the outskirts of the capital city, Fortaleza, Ceará, Brazil, participated in the study. From the Content Analysis, two categories arose: "sharing suffering" and "attitudes and behavior perceived and experienced by caregivers." In-depth narratives revealed marked affection between patients and their family caregivers. Despite poverty, structural violence, unemployment, social prejudice and low salaries endemic in the Northeast of Brazil, the caregivers find effective ways to cope with chronic illness besides creating strategies to diminish suffering caused by the illness.

Key words Care, Family, Chronic obstructive pulmonary disease
\end{abstract}

Resumo O cuidado causa estresse na dinâmica cotidiana da família levando a complicações físicas, mentais e emocionais ao cuidador, perda da liberdade e/ou sobrecarga de cônjuges. Entre março e novembro de 2006, esta pesquisa antropológica examinou o cuidado familiar no contexto da Doença Pulmonar Obstrutiva Crônica (DPOC). Utilizando entrevista etnográfica, narrativa da enfermidade e observação participante objetivouse descrever a reorganização e a convivência familiar com a evolução e a experiência com a DPOC, a percepção de cuidadores familiares sobre as dificuldades e as limitaçôes vivenciadas junto ao doente e as estratégias de enfrentamento da enfermidade. Participaram do estudo seis cuidadores familiares de baixa renda residentes em bairros urbanos pobres da periferia de Fortaleza, Ceará, Brasil. Da Análise de Conteúdo emergiram as categorias: "dividindo sofrimentos" e "atitudes e comportamentos percebidos e vivenciados pelos cuidadores". As narrativas profundas mostraram a afetação significativa entre os enfermos e seus cuidadores familiares. Apesar da pobreza, violência estrutural, desemprego, preconceito social e baixos salários endêmicos no nordeste brasileiro, os cuidadores descobrem maneiras efetivas de lidar com a cronicidade além de criar estratégias para amenizar o sofrimento causado pela doença. Palavras-chave Cuidado, Família, Doença pulmonar obstrutiva crônica 


\section{Introdução}

A avaliação da qualidade do cuidado ${ }^{1}$, seu entendimento nas condições crônicas severas ${ }^{2,3}$, o autocuidado de pacientes crônicos ${ }^{4}$, modelos educativos para cuidados em saúde ${ }^{5}$ e a qualidade de vida do doente determinada pelo nível de cuida$\mathrm{do}^{6}$, são algumas das inquietações da comunidade científica mundialmente. Por outro lado, o cuidado é a causa de estresse na dinâmica cotidiana da família ${ }^{7,8}$, levando à complicações físicas, mentais e emocionais ao cuidador $^{9,10}$, perda da liberdade ${ }^{11,12}$ e/ou sobrecarga dos cônjuges ${ }^{11,13,14}$.

Mais que pensar, imaginar e julgar ${ }^{15}$, cuidar é um ato de atenção, proteção, preocupação, atitudes e sentimentos que leva a uma relação entre pessoas, práticas e ações sociais, comandadas por representações simbólicas acerca da solidarieda$\mathrm{de}^{16}$. Apesar do envolvimento e da forte ligação afetiva pelo outro ${ }^{17}$, o cuidador primário ${ }^{12,18}$ carrega o peso do cuidar, renuncia à sua vida pessoa ${ }^{19}$ e sofre imposição das circunstâncias para assumir esse papel ${ }^{20}$. O desgaste físico, a baixa saúde mental e a diferente percepção da relação matrimonial causada pela dedicação a alguém ${ }^{13,11}$ são vistos como cumprimento do papel de famí$\operatorname{lia}^{21}$, perdendo assim a essência de sua origem no contexto de relações de amor e amizade ${ }^{17}$.

O cuidado torna-se, então, desafiador, porém necessário no contexto da enfermidade crônica $^{14,18,22}$, gerando, infelizmente, uma carga familiar traduzida pelas dificuldades e desafios experienciados com a cronicidade ${ }^{14,21}$, distanciando-se cada vez mais de suas significações bási$\mathrm{cas}^{17}$. Nesse sentido, as experiências com a saúde e a doença permeiam as dimensões objetiva e subjetiva, pessoal e coletiva, universal e cultural. Refletir a relação saúde-doença isoladamente é excluir a influência sócio-cultura ${ }^{23}$ que envolve, além de outros aspectos, a experiência do cuidador no processo saúde-doença-cronicidade ${ }^{12}$, influências mais fortemente percebidas nos países em desenvolvimento que sofrem com a problemática sócio-econômica-cultural.

Assim, o presente artigo envolve o cuidado familiar no contexto da Doença Pulmonar Obstrutiva Crônica (DPOC) através da reorganização e convivência familiar com a evolução e a experiência com a enfermidade ${ }^{24}$. O estudo teve por objetivo descrever a percepção de cuidadores familiares sobre as dificuldades e as limitações vivenciadas junto ao doente e as estratégias de enfrentamento da enfermidade pulmonar crônica.

\section{Métodos}

Entre março e novembro de 2006, esta pesquisa antropológica, foi realizada no domicílio de seis cuidadores familiares de pacientes com Doença Pulmonar Obstrutiva Crônica participantes do Programa de Reabilitação Pulmonar (PRP) de um hospital público de Fortaleza (2.200.000 habitantes), capital do Ceará, no Nordeste brasileiro, que detém uma região Metropolitana marcada pela pobreza, disparidade econômica, desigualdades, segregação social ${ }^{25}$, violência institucional ${ }^{26,27}$ e uma crescente vulnerabilidade pessoal. Entre 1991 e 2000, a distância média entre os $10 \%$ mais ricos e os $40 \%$ mais pobres em Fortaleza, cresceu de 13,3 para 18,7 vezes $^{25}$; a taxa de homicídios foi de $35,4 \%$ do total de habitantes em $2006^{28}$. Esse estudo faz parte de uma ampla investigação que incluiu profissionais de saúde e pacientes com enfermidade pulmonar ${ }^{29}$.

A idade dos informantes-chave variou entre 28 e 60 anos, com média de 39 anos. A seleção foi intencional, segundo a frequência de acompanhamento e os relatos de familiares que detinham o cuidado diário com o enfermo. Desse modo, identificamos cinco $(83,3 \%)$ mulheres, sendo três (50\%) esposas, duas (33,3\%) filhas e um (16,6\%) filho, que assumiram o papel de cuidador familiar. Todas as famílias residiam em favelas, conjuntos habitacionais ou bairros periféricos e apresentavam baixa renda. Metade dos informantes trabalhava fora de casa e $66,6 \%$ emigraram do interior. Quanto à escolaridade, 66,6\% terminaram o ensino fundamental e $33,3 \%$, o ensino médio. Embora todos tenham declarado uma religião $(83,3 \%$ católicos e $16,6 \%$ evangélico), sua prática foi referida por $50 \%$.

Utilizamos a entrevista etnográfica ${ }^{30}$, a narrativa da enfermidade ${ }^{24,31}$ e a observação participante para construir uma "descrição densa" ${ }^{2} \mathrm{da}$ experiência do cuidador de um paciente crônico. Após o contato inicial no hospital, foram realizadas visitas domiciliares nas quais as entrevistas etnográficas foram conduzidas utilizando um guia de tópicos a ser explorado, além do incentivo à narração livre da experiência de cuidar. A coleta de dados na própria residência deixou o informante livre para expressar ideias e estabeleceu rapport (elo afetivo) entre as pesquisadoras, aproximando-as da realidade sociocultural e ambiental da família. A entrevista foi norteada por perguntas abertas: Como você percebe a doença do seu familiar? Descreva as dificuldades 
que você percebe que o paciente sofre por causa da doença. Como vocês enfrentam as dificuldades causadas pela doença? O objetivo da entrevista foi desvelar a perspectiva do cuidador sobre a enfermidade crônica, na própria voz e em linguagem popular. Intercaladas com as entrevistas abertas e aprofundadas, o cuidador foi incentivado a discorrer livremente sobre o seu dia-a-dia com o doente, suas dificuldades, expressando abertamente sua vivência com a cronicidade. Assim, a narrativa da enfermidade não reflete meramente um modelo ou representação estática da doença, mas permite que o informante ordene os acontecimentos, atribuindo os significados como julga relevante à sua vivência, defende Kleinman ${ }^{24}$ e Lira et al. ${ }^{31}$.

Contextualizamos e verificamos o discurso leigo e ampliamos a lente cultural com a observação-participante não estruturada com a qual observamos os informantes-chave no contexto domiciliar com os doentes e com outros membros da família (filhos, neto, irmãos). Durante as visitas, os cuidadores mostraram a estrutura domiciliar (especialmente os dormitórios dos pacientes), o ambiente da casa mais frequentado, as medicações, explicaram a reorganização dos compartimentos após o surgimento dos sintomas e externaram suas preocupações com o enfermo no decorrer da evolução da DPOC.

As entrevistas foram gravadas e transcritas integralmente com nomes fictícios, preservando o anonimato dos informantes. As observações foram anotadas num diário de campo, e posteriormente em texto descritivo seguido da organização e da codificação de acordo com as etapas da Análise de Conteúdo ${ }^{33}$. Das análises emergiram duas categorias principais: "dividindo sofrimentos" e "atitudes e comportamentos percebidos e vivenciados pelos cuidadores".

Para a análise e a interpretação dos dados inspiramo-nos na "interpretação semântica contextualizada" de renomados antropólogos ${ }^{34}$, interligando a experiência individual dos cuidadores aos sistemas de significação atribuídos; e as ações, realizadas ou não, diante dos condicionantes estruturais. Finalmente, interpretamos os resultados à luz da Antropologia Médica. A pesquisa foi aprovada pelo Comitê de Ética e Pesquisa do Hospital de Messejana Dr. Carlos Alberto Studart Gomes.

\section{Resultados}

\section{Dividindo sofrimentos}

O cuidador familiar compartilha a dor e o sofrimento da pessoa com DPOC de modo mais frequente e, muitas vezes, mais profundo que o profissional. É fonte tanto de angústia e estresse para o doente quanto de apoio. Presencia a depressão, a impaciência, a agitação, as reclamações de que o remédio não tem efeito, a tristeza do paciente por causa do seu problema, a baixa autoestima, crises de tosse ou de falta de vontade de viver. O mais difícil segundo Rosa, 41 anos, comerciante, filha de D. Maria, 67 anos, é presenciar uma crise de dispneia na qual a mãe fica roxa, morrendo ali na sua frente exigindo sua atitude rápida em preparar o aerosol para aliviar a falta de ar: Ela vinha roxa, sem um pingo de oxigênio. (...) Mas tava tão cansada que ela não falava. Aí eu disse: Pelo amor de Deus, mãe! Porque a senhora se mata e me mata também, viu! Com os olhos cheios de lágrimas, Ana, 28 anos e dona de casa, relembra com tristeza o momento em que D. Joana, sua mãe, foi transportada às pressas para o hospital quando passava uns dias no interior. Foi chocante ver sua mãe com rosto e pele de cadáver e a lingua de papagaio.

Vivenciar o dia-a-dia do doente permite ao cuidador acompanhar a evolução dos sintomas e perceber sua influência na restrição de atividades da vida diária. Presencia a relutância de seus familiares em seguir as orientações quanto à medicação, ao uso de oxigênio (número de horas e ocasiões em que deve usar) ou à realização do aerossol. Compartilha o choro angustiado do doente, a falta de sono, rodando pra cá e pra lá chegando a acompanhá-lo até a rua pra tomar um ar ou ajudando-o a balançar-se nas cadeiras.

As informantes consideradas "esposas-cuidadoras" relataram mudanças no ato sexual que atingiu à total abstinência pela falta de ar do esposo, assemelhando-se a impotência sexual como relata Lúcia, 37 anos, casada há 15 anos com Antônio, diagnosticado com DPOC há seis anos. Lúcia entende que é uma situação delicada e, por isso, não deixa transparecer que percebe a dificuldade do marido, a fim de evitar "maus pensamentos" de sua parte: Fica cansado. E cuuuuuuuusta! Mas é mole, ele. Mas também eu não digo, senão ele vai dizer: 'Tá me achando mole, vai atrás de outro!'. A esposa-cuidadora também acompanha a dificuldade do marido para pegar peso durante 
o trabalho, subir escadas, aguar plantas etc., ocorrendo aos poucos uma inversão de papéis quando esta passa a realizar atividades antes atribuídas ao homem da casa, afirma D. Tereza, 60 anos, dona de casa e esposa de Sr. João. Ela sofre ao observar a culpa que o esposo coloca em si por adquirir a doença, ao ouvir histórias de arrependimento de seus maus comportamentos na juventude e seu desabafo sobre o medo da morte. Seu sofrimento começou muito antes do surgimento da doença quando presenciava as farras do Sr. João e o seu exagero em bebidas e cigarros.

Rosa, 41 anos, é uma dos doze filhos de D. Maria, 67 anos, com diagnóstico de DPOC há 10 anos. Vendedora de roupas há 12, divide seu dia entre administrar sua pequena loja no quintal da casa, cobrar pagamento de seus clientes e cuidar de sua mãe no que diz respeito à medicação, consultas médicas, reposição do oxigênio suplementar e alimentação. É a única pessoa em quem D. Maria confia para acompanhá-la. Por estar sempre perto, apesar de não morar na mesma casa, percebe o sofrimento da mãe em sentir-se presa por um cabresto (tubo nasal de oxigênio) como um cavalo sem poder mover-se, deslocar-se. Sente o preconceito no olhar das pessoas nas ruas como se um balão de oxigênio fosse coisa de outro mundo e o afastamento de outros quando elas se aproximam como se fosse uma doença contagiosa. O olhar de todos na igreja ao entrar o extraterrestre fez com que D. Maria deixasse de frequentar as missas dominicais, participando pela televisão e, assim, isolando-se da sociedade: Eu acho que pensam assim: essa mulher tem uma doença contagiosa! E ela ficava muito angustiada. Hoje em dia que ela ainda sente muito é o único ambiente é dentro da igreja. [...] quando ela entra parece que vai entrando assim um extraterrestre que vai chamando a atenção de todo mundo e aí todo mundo se vira!

Além de vivenciar essas situações, Rosa desabafa em forte tom de voz, que convive com a falta de compreensão da maioria de seus irmãos sobre as limitações de sua mãe, a falta de conhecimento da doença e a insensibilidade em relatar problemas que desencadeiam uma crise, sendo Rosa a mediadora entre os dois lados: É difícil porque um se conscientiza do problema dela, mas outros não. Ah, a mamãe é mais forte do que nós, ela tem mesmo é que saber de tudo! Vocês é que pensam! Então, eu não posso mudar a cabeça de cada um.

Outro desgaste para o cuidador é a hospitalização por alterar a rotina da casa já modificada pela doença. Saber que o estado de saúde de seu familiar é ruim e vê-lo morrendo (em crise) é muito pesado pra quem convive. Também é desanimador, ao receber o diagnóstico da doença, ouvir do profissional de saúde que aquela foi a primeira, mas não a última crise, como ouviu D. Tereza, 60 anos, ainda no hospital, quando se recuperava do susto da primeira crise de dispneia do esposo. Assim, a experiência hospitalar origina nos cuidadores o medo de crises com internamentos, pois causa sofrimento quando surge entre curtos intervalos de tempo como relembra Carlos, 36 anos, casado, um filho, cuidador de sua mãe, D. Rosa, 67 anos. Faltando ao emprego, Carlos acompanhou a mãe por vários internamentos intermitentes, antes de iniciar o tratamento com oxigênio suplementar em casa: Às vezes saía do hospital não dava nem 15 dias, já tinha que voltar de novo. Passava 15 dias, 20, 10, chegava em casa passava uma semana, duas... quando passava três era uma alegria muito grande... Ressalta que no ano anterior ao recebimento do concentrador de oxigênio, sua mãe vivia de hospital, ou seja, esteve mais dias internada do que em casa, o que levava a uma constante tristeza no olhar de D. Rosa e a uma carga elevada para Carlos.

Além da sobrecarga de cuidados do paciente durante o dia, o cuidador também sofre durante a noite com o barulho gerado pelo aparelho de oxigênio, não descansando o suficiente para enfrentar o dia seguinte. As crises de tosse durante a noite também incomodam como declara Lúcia, 37 anos, dona de casa, casada com Antônio, de 41 anos: Ô Antônio, pelo amor de Deus, deixa eu dormir... Tu tá fazendo muita zuada! No quarto pequeno e sem janela, Lúcia sente-se incomodada, perde o sono, mas ao mesmo tempo pensa que é algo incontrolável e procura não reclamar para evitar estresse ao seu companheiro. Mas aí eu fico com pena dele porque eu sei que é uma coisa que ele não tem aquele controle.

Apesar de sentimentos ruins permearem o dia a dia do cuidador, também há momentos em que este se sente feliz e realizado como, por exemplo, ao conseguir o aparelho de oxigênio para seu familiar quando tantos pacientes não o têm, a medicação que não pode ser comprada pela falta de dinheiro ou uma vaga para iniciar o Programa de Reabilitação Pulmonar. São vitórias no que diz respeito ao tratamento e uma esperança para melhorar a falta de ar.

\section{Atitudes e comportamentos percebidos e vivenciados pelos cuidadores}

Ao evoluir, a DPOC invade a vida do doente, conduzindo-o a mudanças de comportamento e 
a atitudes facilmente percebidas por aquele que está diariamente do lado. Por não entender a doença, suas causas e consequências, o paciente se isola das pessoas, não fala perto de familiares e mantém seus utensílios separados por medo de pegar nos outros. Consequentemente, o cuidador modifica sua rotina, acompanhando o doente ao ponto de ônibus pelo medo de uma crise repentina e ao Programa de Reabilitação Pulmonar para aprender e estimulá-lo a realizar os exercícios em casa. Também dorme no mesmo ambiente para não deixá-lo sozinho durante a noite e ajuda durante o banho para evitar que se sinta mal. Uma das tarefas de D. Tereza, 60 anos, esposa do Sr. João, 69 anos, sapateiro, era ajudá-lo durante o banho, diminuindo o seu esforço físico e, consequentemente, a falta de ar: Aparando água na pia... eu que banhava ele porque ele cansava. Eu banhava ele de bermuda. Eu dizia: 'Não toma dentro do banheiro que tu pode sentir alguma coisa!' Porque o médico já disse, ele tem isso de falta de ar, ataca muito na hora do banho. Faz muito movimento pra se esfregar. Eu comprei uma esponja pra banhar ele. Eu que limpava ele todinho. 'Fica sem se mexer!' E eu mesmo passava. Apesar do desafio de aceitar tomar banho sentado e ter a ajuda da esposa, a estratégia mostrou ao Sr. João que a economia de energia usada para tomar banho não lhe causava falta de ar.

Diante das dificuldades apresentadas pela enfermidade, tanto o cuidador como o paciente se envolve com a oração, a religião e a crença. Acreditam que, de algum modo, conseguirão forças pra superar as crises, os internamentos, os sufocos do dia-a-dia. O cuidador percebe que atividades manuais como crochê, pontos de cruz e exercícios de Yoga desviam a mente dos doentes sobre seus problemas familiares, acalmando a respiração e evitando uma crise de falta de ar. Por visitar a mãe várias vezes ao dia, Rosa já percebe quando ela se sente mais tranquila e aliviada dos sintomas. Os exercícios que ela aprendeu da bombinha, o que ela aprendeu na Yoga dos dedinhos. [...] ela passa o dia agarrada nesse crochezinho. [...] O que faz ainda mais ela esquecer os problemas é quando ela faz esse crochezinho ou ponto de marca, esse crochê, que ela fica tão entretida que você fala com ela e ela não percebe! É a única forma que eu vejo ela se sair melhor.

A tarefa de cuidar, para nossos informantes, é árdua por relacionar-se a uma doença crônica e inicia-se ao receber o diagnóstico, momento destacado como um choque para todos. Porém, os cuidadores deste estudo mostraram-se fortes e enfrentaram os problemas de frente apesar da situação econômica desfavorável. Buscaram médicos, lutaram pela medicação, pediram dinheiro de um e de outro para o aluguel do aparelho de oxigênio ou procuraram trabalho fora de casa para melhorar a situação financeira prejudicada pela enfermidade do companheiro. Orientaram os doentes a não sair de casa com sol forte sol, a evitar a quintura e a poeira, não fazer extravagância, não trabalhar, em fim, não fazer nada que causasse esforço físico. Apesar de orientar, apoiar e ajudar há momentos em que a impotência surge diante de estados depressivos do paciente ou de uma crise inesperada. Sentem-se incapacitados de controlar a situação e de aliviar o sofrimento do ente querido, ficam tristes em não poder ajudar, sentem-se fracos, impotentes e sem alternativas para lutar contra a doença no momento da crise.

Carlos, 36 anos, casado, um filho, mora com sua mãe e compara o cuidado de uma doença crônica a uma guerra na qual, às vezes, faltam armas necessárias para entrar no combate, neste caso, entre a vida e a morte. Porque nós aqui não podemos fazer nada nesse caso dela porque a gente não tem como! Não tem arma pra poder... ajudar ela. O problema dela é um problema interno, é uma doença que a gente sabe que não tem cura, e ela também já sabe.

A doença crônica conduz à inversão de papéis como no caso de Ana, 28 anos, mãe solteira que renunciou o filho para cuidar integralmente da mãe, D. Joana, 58 anos, diagnóstico de DPOC há um ano. Sente-se sozinha e com todo o peso do cuidar, mas naquele momento a saúde de sua mãe era mais importante que seu filho ou que qualquer relacionamento amoroso: Tem que ser uma pessoa forte do lado dela, não chorar junto com ela. [...] Eu me dediquei de corpo, alma e tudo pra tratar, era eu sozinha... todo mundo vinha, visitava, mas ninguém ficava. Quem fica do lado dela sou eu. É comida, é remédio, é tudo. Foi uma mudança na minha vida. Tudo dela caiu só em cima de mim! Cuidar dela foi difícil pelas coisas que eu tive de... não chorar na frente dela, quando ela estava chorando ter que levantar ela, embora aquilo me doesse, mas eu tinha que dizer a verdade pra ela! Às vezes ela estava chorando, e mandava eu arranjar um amparo. Mãe, eu não quero amparo! O que eu estou querendo agora é sua saúde! Porque amparo a gente encontra em qualquer esquina, e saúde ninguém encontra!. Aos poucos seus cuidados foram refletidos no ganho de peso da D. Joana, nos banhos sem sua ajuda, na vontade em realizar os exercícios, ou seja, uma melhora física e emocional significativa. 
Está explícito, assim, o amor e a dedicação dos sujeitos desta pesquisa, por seus familiares, que cuidam de maneira incondicional e aprendem a conviver com a doença. $O$ fato de o marido ter DPOC não significa para Fátima, 35 anos, mulher que aprendeu a trabalhar fora de casa para melhorar a renda familiar, a separação ou o abandono do esposo no meio das dificuldades. Ao contrário, foi capaz de lutar pela estabilidade financeira do casal e assumir a carga do cuidar com paciência: Quando a gente gosta a gente vai até o fim, né. É pedir força a Deus, eu peço força a Deus, pra Deus me dá força, ajuda a ele e assim a gente vai levando. Cuido dele, tenho a maior paciência com ele... é assim. A convivência com a cronicidade gera no cuidador a conformação, aceitação do fato de que não podem mais fazer nada, somente tocar a vida pra frente. Torna-se mais fácil ou menos pesado, quando tanto o cuidador como o paciente entendem que a doença não tem cura, mas que podem viver bem na medida em que aprende sobre a enfermidade, entende os seus limites e estratégias de controle dos sintomas.

Carlos, 36 anos, via em sua mãe um exemplo de mulher forte que, apesar de viúva, criou bem seus quatro filhos. Vê-la hoje ligada a um aparelho de oxigênio e dependente de outras pessoas pra ajudá-la em situações simples como trocar de roupa ou preparar o aerosol, deixa-o muito triste, mas aos poucos, se adapta à situação: No início era ruim porque a gente não tinha noção. $O$ médico tinha falado que com o tempo ia ser desse jeito que está agora, mas a gente pensava que poderia ser um pouco de exagero, mas do jeito que veio se instalando as coisas, chegou num ponto crítico. Ninguém sabia direito, o médico foi explicando, a gente foi se adaptando, foi se acostumando. A gente já está levando mais ou menos. Já tem uns pontos que a gente conhece!

\section{Discussão}

Através deste estudo desvelamos a racionalidade leiga ${ }^{35}$ sobre a enfermidade do outro ${ }^{24,36,37}$, o cuidado como demonstração de amor ${ }^{17}$, a humanização do cuidado ${ }^{26}$, os obstáculos do ato de cuidarr $^{38}$, a inversão de papéis ${ }^{29}$ e o agir popular diante a enfermidade ${ }^{37,39}$.

O cuidador familiar de pessoas com DPOC em um país em desenvolvimento, muitas vezes em situações de pobreza, convive com as limitações e as restrições causadas pela falta de ar e o medo das crises que podem culminar com uma internação, como vivenciou Ana com sua mãe.
Diferentemente, pesquisa realizada em país desenvolvido com 214 idosos para comparar o estresse de familiares de 64 pacientes com internação domiciliar e 40 com cuidados hospitalares agudos tradicionais ${ }^{7}$ revelou que a internação domiciliar está associada com baixos níveis de estresse nos familiares quando comparado aos daqueles com cuidados hospitalares tradicionais. Apesar do presente estudo não apresentar internação domiciliar, a carga de estresse dos cuidadores nos domicílios é bastante significativa, uma vez que envolve um contexto social e econômico bastante afetado negativamente. A situação mais forte associada ao estresse das famílias americanas relacionou-se à dificuldade de presenciar a perda da capacidade do autocuidado dos seus familiares, fato também revelado por nossos cuidadores nordestinos que passaram a ajudar nas atividades básicas dos doentes. Adicionalmente, a carga desse estresse é amplificada pelas condições de pobreza urbana e de violência estrutural ${ }^{40}$ que nossos informantes sofrem e enfrentam diariamente.

Nesse estudo é explícita a representação de filhos ou cônjuges como cuidador familiar que mudaram suas rotinas e aumentaram a carga de trabalho pra assumir o seu papel. Corroborando com esses achados, ao aplicar o questionário Family Dynamics Measure a 36 familiares de pacientes finlandeses com oxigenioterapia domiciliar e 29 de internados, Kanervisto et al. ${ }^{41}$ encontraram que as esposas de pacientes com doença crônica apresentavam uma carga elevada em seu papel dentro da família e mais responsabilidade por assumirem a parte financeira da casa antes de responsabilidade do marido, mostrando uma certa globalidade da sobrecarga de cuidado às esposas. Porém, devido ao exaustivo trabalho manual e aos baixos salários das mulheres nordestinas que ganham, em média, 300 reais por mês, o ônus de complementar a renda familiar parece ser uma carga ainda mais pesada.

O desconhecimento sobre a DPOC e como enfrentar sua evolução, leva à angústia e ao sofrimento, observados nos relatos dos sujeitos. Seguindo a abordagem qualitativa, estudo através de grupos focais com 13 sujeitos de baixa renda, sendo $62 \%$ pacientes com DPOC $^{42}$ revelou a ausência de informação básica de pacientes americanos, o que parece mostrar que a falta de conhecimentos e informação sobre a doença abrange também países desenvolvidos. Em geral, os pacientes desconheciam a presença de um pulmão afetado e não sabiam nomear a enfermidade, realçando a necessidade de um processo educativo para tornarem-se ativos consideran- 
do a saúde de seu pulmão e o manejo de sua condição ${ }^{42}$. Em diferente contexto, porém compartindo a mesma carência, a baixa escolaridade dos nossos pacientes nordestinos (maioria somente com o ensino fundamental) exige uma adaptação de materiais educativos para facilitar sua compreensão ${ }^{43}$.

As declarações dos nossos informantes revelaram a ausência de ajuda e de entendimento dos familiares e/ou pessoas que convivem com o doente gerando sobrecarga ao cuidador. Para descrever a experiência da qualidade de vida de mulheres que cuidam de esposos com DPOC, Ber$\mathrm{gs}^{11}$ realizou um estudo fenomenológico nos Estados Unidos que identificou a insatisfação de esposas com respeito à falta de lazer e de suporte dos amigos e da família e de condições de cuidados de saúde, aspectos que, em parte, coincidem com o deste estudo, pois estas não revelaram a ausência de lazer e de cuidados com a saúde. Apesar da insatisfação das esposas no estudo de Ber$\mathrm{gs}^{11}$, as participantes, tanto as americanas como as nordestinas, se mostraram disponíveis a cuidar dos seus familiares até o último momento.

Cuidar sempre gera sobrecarga, porém quando se refere a enfermidades crônicas como a DPOC o peso parece ainda maior. Em estudo holandês, com 357 cônjuges de pacientes com falência cardíaca, predominantemente mulheres (75\%) e a maioria com baixo nível de escolarida$\mathrm{de}^{13}, 23 \%$ relatou alteração nas atividades diárias e $16 \%$ indicaram perda de força física resultantes do processo de cuidar. Funcionalidade física, saúde mental e percepção da relação matrimonial baixas revelaram escores significativamente altos de carga dos cuidadores investigados. A baixa percepção da relação matrimonial também foi identificada no presente estudo quanto à atividade sexual comprometida pela falta de ar, fato superado pelas esposas. Reforçando o comprometimento da atividade sexual nesses pacientes, estudo sobre a sexualidade de 25 sujeitos com DPOC através de dois questionários ${ }^{44}$ verificou que os homens com DPOC tinham qualidade de vida sexual significativamente baixa em todos os domínios. As mulheres com DPOC relataram baixa frequência de intimidade sexual e baixa qualidade de vida sexual global, fato que não podemos comparar uma vez que não houve revelações sobre a atividade sexual de mulheres com DPOC no presente estudo.

Recente pesquisa de país desenvolvido ${ }^{45}$, através de entrevista semiestruturada, descreveu como cinco pessoas com DPOC severa e quatro cônjuges lidam com a vida diária. Os doentes relataram que em determinados momentos eram incapazes de realizar atividades de casa leves, precisando da ajuda de seus cônjuges para aguar plantas, por exemplo, e que os familiares foram os primeiros a ajudar tanto em tarefas mais pesadas como nas mais simples, achados compartilhados pelos participantes deste estudo. Os autores também revelaram a participação dos pacientes em cursos de reabilitação, juntamente com os cônjuges, e uso de técnicas de respiração para diminuir a falta de ar. Restrições nas atividades do cotidiano, o preconceito das pessoas na rua e a oxigenioterapia para o alívio dos sintomas também foram aspectos encontrados no estudo, corroborando os relatos dos nossos informantes.

Pesquisa qualitativa realizada no Brasil, utilizando discurso do sujeito coletivo com 16 cuidadores de idosos portadores de doenças crônicas atendidas em um Centro de Saúde Escola em São Paulo ${ }^{19}$, aponta prejuízo da vida social do cuidador e insatisfação da maioria dos sujeitos com seus familiares que, segundo eles, poderiam ajudar, mas não o fizeram, assim como Rosa desabafou sobre seus irmãos. Igualmente aos nossos resultados, a religião também foi uma forma de enfrentar as dificuldades do cuidado de pessoas idosas com doenças crônicas, fato que parece atingir uma perspectiva mundial quando se refere à busca de ajuda para a cura.

Os sintomas da DPOC desafiaram nossos informantes e seus familiares, exigindo mudanças, às vezes, nunca imaginadas, adaptações à nova realidade e preparação para um futuro incerto dentro da dura realidade dos países em desenvolvimento. Estudo quantitativo holandês com 1.093 cônjuges de doentes crônicos, dos quais $58,1 \%$ dos sujeitos tinha nível educacional básico e $49,3 \%$ eram mulheres ${ }^{12}$, ressalta que mais da metade dos sujeitos percebem que a doença crônica de seu parceiro colocou uma tensão em sua vida pessoal de uma maneira ou de outra. Reforçando as mudanças consequentes à enfermidade, entrevistas realizadas com cinco casais na Islândia ${ }^{46}$ mostraram que as esposas apresentavam dificuldade severa para respirar e identificou uma situação financeira limitada e esposos impedidos de trabalhar para cuidar das esposas. Consequentemente, foram desenvolvidas outras rotinas para lidar com as dificuldades da mesma maneira que nossos informantes. A afetação da DPOC na vida dos pacientes não depende da evolução econômica ou social de um país, porém a forma de como sua evolução será enfrentada, se com mais ou menos recursos. 
O pequeno número de participantes e a presença de apenas um cuidador do sexo masculino podem ser considerados como limitações do estudo. Porém, os relatos profundos apresentados mostram a percepção dos cuidadores familiares sobre as dificuldades e as limitações vivenciadas junto ao doente, e as estratégias de enfretamento da enfermidade pulmonar crônica. A DPOC afeta significativamente tanto a vida dos doentes como de seus familiares próximos, em especial o que se encarrega do cuidado. Porém, apesar da pobreza, da violência estrutural, do desemprego, do preconceito social e dos baixos salários endêmicos no nordeste brasileiro, os cuidadores descobrem como lidar com a cronicidade e criam estratégias para amenizar o sofrimento causado pela doença.

Com base nos achados deste estudo e considerando que o cuidador tem importante papel na vida do paciente pulmonar crônico, futuras pesquisas podem estar voltadas para explorar suas necessidades dentro do processo de cuidar e a influência de gênero do cuidador nos cuidados, no ponto de vista do paciente.

\section{Colaboradores}

JMS Pinto foi autora da concepção do estudo, realizou a revisão da literatura, coleta e análise dos dados e redação inicial do artigo. MK Nations orientou as etapas da pesquisa, participou das discussões dos dados e colaborou na redação do artigo.

\section{Agradecimentos}

À Fundação Cearense de Apoio à Pesquisa (FUNCAP) e ao Hospital de Messejana Dr. Carlos Alberto Studart Gomes pelo apoio na realização da pesquisa. 


\section{Referências}

1. Bokhour BG, Pugh MJ, Rao JK, Avetisyan R, Berlowitz DR, Kazis LE. Improving methods for measuring quality of care: a patient-centered approach in chronic disease. Med Care Res Rev 2009; 66(2):147166.

2. Kahn KL, MacLean CH, Liu H, Rubenstein LZ, Wong AL, Harker JO, Chen WP, Fitzpatrick DM, Bulpitt KJ, Traina SB, Mittman BS, Hahn BH, Paulus HE. The complexity of care for patients with rheumatoid arthritis: metrics for better understanding chronic disease care. Medical Care 2007; 45(1):55-65

3. Roche N. Quality of care in chronic obstructive pulmonary disease. Rev Mal Respir 2006; 23(Supl. 3):44-56.

4. Cicutto LC, Brooks D. Self-care approaches to managing chronic obstructive pulmonary disease: a provincial survey. Respir Med 2006; 100(9):1540-1546.

5. Ross F, Harris R. Can interprofessional education make a difference in the care of people with chronic disease? Chronic Illn 2005; 1(1):81-86.

6. Díez JM, Alonso JLI, González-Moro JMR, Ramos PL, Cano JMB, París JM. Quality of life with chronic obstructive pulmonary disease: the influence of level of patient care. Arch Bronconeumol 2004; 40(10):431-437.

7. Leff B, Burton L, Mader SL, Naughton B, Burl J, Koehn D, Clark R, Greenough WB 3rd, Guido S, Steinwachs D, Burton JR. Comparison of stress experienced by family members of patients treated in hospital at home with that of those receiving traditional acute hospital care. JAGS 2008; 56(1):117-123.

8. Kanervisto M, Paavilainen E, Heikkila J. Family dynamics in families of severe COPD patients. $J$ Clin Nurs 2007; 16(8):1498-1505.

9. Zamora ZEH. Cuidadores del adulto mayor residente em asilos. Index Enferm 2006; 15(52-53):4044.

10. Silveira TM, Caldas CP, Carneiro TF. Cuidando de idosos altamente dependentes na comunidade: um estudo sobre cuidadores familiares principais. Cad. Saúde Pública 2006; 22(8):1629-1638.

11. Bergs D. "The hidden client" - woman caring for husbands with COPD: their experience of quality of life. Journal of Clinical Nursing 2002; 11(5):613-621.

12. Baanders AN, Heijmans MJWM. The impact of Chronic Diseases - The partners perspectives. Fam Cummunity Health 2007; 30(4):305-17.

13. Luttik ML, Jaarsma T, Veeger N, Tijssen J, Sanderman R, Veldhuisen DJ. Caregiver burden in partners of Heart Failure patients; limited influence of disease severity. European Journal of Heart failure 2007; 9(6-7):695-701.

14. Creese J, Bédard M, Brazil K, Chambers L. Sleep disturbances in spousal caregivers of individuals with Alzheimer's disease. International Psychogeriatrics 2008; 20(1):149-161.

15. Hollanda AB. Dicionário do Aurélio. [acessado 2009 jul 10] [Documento da Internet]. Disponível em: http://www.dicionariodoaurelio.com/
16. Torres SVS, Sé EVG, Queiroz NC. Fragilidade dependência e cuidado: desafio ao bem-estar dos idosos e de suas famílias. In: Diogo MJD, Neri AL, Cachioni M, organizadores. Saúde e qualidade de vida na velhice. Campinas: Alínea; 2004.

17. Boff L. Saber cuidar: ética do humano - compaixão pela terra. Rio de Janeiro: Vozes; 1999.

18. Hauser JM, Chang CH, Alpert H, Baldwin DW, Emanuel EJ, Emanuel L. Who's caring for whom? Differing perspectives between seriously ill patients and their family caregivers. Am J Hosp Palliat Care 2006; 23(2):105-112.

19. Simonetti JP, Ferreira JC. Estratégias de coping desenvolvidas por cuidadores de idosos portadores de doença crônica. Rev Esc Enferm USP 2008; 42(1):19-25.

20. Gregory S. Living with chronic illness in the family setting. Sociology of Health \& Illness 2005; 27(3):372392.

21. Sales E. Family Burden and Quality of life. Quality of life research 2003; 12(Supl. 1):33-41.

22. Langa KM, Fendrick AM, Flaherty KR, Martinez FJ, Kabeto MU, Saint S. Informal caregiving for chronic lung disease among older Americans. Chest 2002; 122(6):2197-2203.

23. Concone MHVB. Os sentidos da Saúde: uma abordagem despretensiosa. In: Goldenberg P, Marsiglia RMG, Gomes MHA, organizadores. O Clássico e o Novo: tendências, objetos, e abordagens em ciências sociais e saúde. Rio de Janeiro: Editora Fiocruz; 2003.

24. Kleinman A. The Illness Narratives: Suffering, Healing \& The Human Condition. New York: Basic Books; 1988.

25. Bernal C. Cidade extrapola seus limites. [acessado 2006 out 10] [Documento da Internet]. Disponível em: http://adm.noolhar.com

26. Nations MK, Gomes AMA. Cuidado, 'cavalo batizado' e crítica da conduta profissional pelo paciente-cidadão hospitalizado no nordeste brasileiro. Cad. Saúde Pública 2007; 23(9):2103-2112.

27. Gomes AMA, Nations MK, Luz MT. Pisada como pano de chão: experiência de violência hospitalar no Nordeste brasileiro. Saúde Soc. São Paulo 2008; 17(1):61-72.

28. Waiselfisz JJ. Mapa de violencia dos municípios brasileiros. Brasília: RITLA, Instituto Sangari, Ministério da Saúde, Ministério da Justiça, Ideal Gráfica e Editora; 2008

29. Pinto JMS, Vieira, Souza LJE, Nations MK. Sopro de vida: experiência com a doença pulmonar obstrutiva crônica na pobreza urbana de Fortaleza, Ceará, Brasil. Cad. Saúde Pública 2008; 24(12):2809-2818.

30. Spradley JP. The ethnographic interview. New York: Holt, Rinehart and Winston; 1979.

31. Lira G, Catrib AMF, Nations MK. A narrativa na pesquisa social em saúde: perspectiva e método. Rev. Brasil. em Promoção da Saúde 2003; 16(1-2):59-66.

32. Geertz C. A. Interpretação das Culturas. Rio de Janeiro: Koogan; 1989.

33. Bardin L. Análise de conteúdo. Lisboa: Edições 70; 1977. 
34. Bibeau G, Corin EE. From Submission to the text to interpretive violence. In: Bibeau G, Corin EE, editors. Beyond textuality: asceticism and violence in anthropological interpretation. Berlin: Mouton de Gruyter; 1995.

35. Good BJ. Medicine, Rationality and Experience: an anthropological perspective. The United Kingdom: Cambridge Press; 1994.

36. Kleinman A. What really matters: living a moral life amidst uncertainty and danger. Oxford: Oxford University Press; 2006.

37. Uchoa E, Vidal JM. Antropologia médica: elementos conceituais e metodológicos para uma abordagem da saúde e da doença. Cad. Saúde Pública 1994; 10(4):497-504.

38. Nagahama EEI, Santiago SM. Práticas de atenção ao parto e os desafios para humanização do cuidado em dois hospitais vinculados ao Sistema Único de Saúde em município da Região Sul do Brasil. Cad. Saúde Pública 2008; 24(8):1859-1868.

39. Nations MK, Monte CMG. I'm not dog, no!: cries of resistance against cholera control campaigns. Social Science \& Medicine 1996; 43(6):1007-1024.

40. Farmer P, Connors M, Simmons J. Women, poverty and AIDS: sex, drugs, and structural violence. Monroe: Common Courage; 1996.

41. Kanervisto M, Paavilainen E, Astedt-Kurki P. Impact of Chronic Obstructive Pulmonary Disease on family functioning. Heart and Lung 2003; 32(6):360-367.

42. Parker DR, Goldman RE, Eaton CB. A qualitative study of individuals at risk for or who have Chronic Obstructive Pulmonary Disease: What do they understand about their disese? Lung 2008; 186(5):313316.

43. Pinto JMS, Nations MK. Sopro de vida: o bem-viver com a Doença Pulmonar Obstrutiva Crônica. No prelo 2010.

44. Kaptein A, Klink RCJ, Kok F, Scharloo M, Snoei L, Broadbent E, Bel EH, Rabe KF. Sexuality in patients with asthma and COPD. Respiratory Medicine 2008; 102(2):198-204.

45. Kanervisto M, Kaistila T, Paavilainen E. Severe chronic obstructive pulmonary disease in a family's everyday life in Finland: perceptions of people with chronic obstructive pulmonary disease and their spouses. Nursing and Health Sciences 2007; 9(1):40-47.

46. Jonsdottir H. Research-as-if-practice: a study of family nursing partnership with couples experiencing severe breathing difficulties. J Fam Nurs 2007; 13(4):443-460.

Artigo apresentado em 29/07/2010

Aprovado em 28/03/2011

Versão final apresentada em 09/04/2011 